\title{
LIII. On the disintegration of platinum and palladium wires at high temperatures
}

\author{
Walter Stewart M.A. D.Sc.
}

To cite this article: Walter Stewart M.A. D.Sc. (1899) LIII. On the disintegration of platinum and palladium wires at high temperatures, Philosophical Magazine Series 5, 48:294, 481-484, DOI: 10.1080/14786449908621440

To link to this article: http://dx.doi.org/10.1080/14786449908621440

曲 Published online: 08 May 2009.

Submit your article to this journal $\lceil\pi$

Џ Article views: 2

Q View related articles $\asymp$ 
there is a second good cleavage parallel to the possible faces which have been selected as the form $\{110\}$.

'The fracture is conchoidal. The specific gravity of the crystal was determined by suspending it in methylene iodide, and has the value $3 \cdot 185$ at $22^{\circ} \mathrm{C}$. The hardness is about that of felspar. The lustre is vitreous, but pearly on $b$. The plane of the optic axes is 010 , the acute bisectrix is perpendicular to 001 , and the crystal is optically positive.

By refraction through a prism bounded by two of the faces of the form $v$ it was possible to obtain the value of the index of refraction, $\gamma=1.622$ (sodium light), of a ray vibrating parallel to the acute bisectrix. By immersing the crystal in a liquid of about the same refractive index as itself, an approximate value for the angle between the optic axes was obtained, $2 \mathrm{~V}=69 \frac{1}{2}^{\circ}$.

Chemical examination of a portion of the crystal has shown it to be a hydrated silicate of sodium and calcium containing about 6 per cent. of oxide of tin, which seems to replace an equivalent quantity of silica.

Before the blowpipe the substance loses water, but remains infusible; it is not dissolved by concentrated hydrochloric acid.

IIII. On the Disintegration of Platinum and Palladium Wires at High Temperatures. By Walter STeWart, M.A., D.Sc., late 1851 E.xhibition Science Scholar, University of Glasgow*.

A CCORDING to Aitken's $\uparrow$ investigations, air which has A been freed from dust has partially lost the power of forming clouds in the presence of water vapour. Prof. 0 . Lodge $f$ found that the power is recovered after a platinum wire has been brought to a "glowing" temperature by an electric current in the dust-free air. From this it has been concluded that solid particles are projected from the wire, or that the wire suffers disintegration; and under suitable conditions a dark-coloured deposit is seen on the walls of the vessel containing the air after the glowing. Elster and Geitel § observed that in an atmosphere of hydrogen a glowing platinum wire does not disintegrate. This was confirmed by Nahrwold \|, who determined also by direct weighing the amount of the disintegration of the glowing wire in air. Nahrwold concluded that the disintegration, if not determined,

* Communicated by Lord Kelvin.

+ Aitken, "On Dust, Fog, and Clouds," Trans. R.S.E. 1883; Proc.

R.S.E. 1881, vol. xi. pp. 14, 122; ' Nature', 1883.

† Proi, O. Lodge, 'Nature,' vol, xxxi. p. 268 (1885).

\& Elster and Geitel, Wied. Ann. xxxi. p. 126 (1887).

II R. Nahrwold, Wied. Ann. xxxi. p. 467 (1887); xxxv, p. 116 (1888). Phil. Mag. S. 5. Vol. 48. No. 294. Nov. 1899. 2L 
was at least materially favoured by the presence of atmospheric air ; he considered that the oxygen of the air was the potent agent.

The following is a description of some experiments on the disintegration of platinum and palladium wires brought by. an electric current to a "glowing" temperature in air, hydrogen, nitrogen, and oxygen at various temperatures. The temperature of the glowing wire ought to be independent of the nature of the surrounding gas ; to effect this object the specific resistance of the wire was kept constant by a proper regulation of the current strength.

The wire to be experimented upon was suspended (fig. 1) by short thick platinum hooks soldered to the thick copper

Fig. 1.

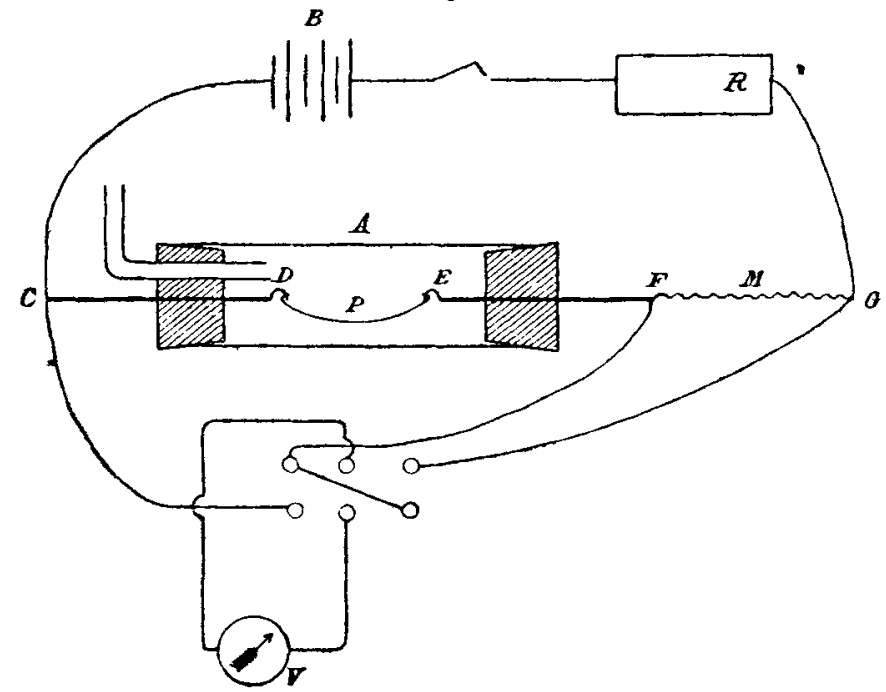

wires CD, EF. A current from a battery $B$ passed through an adjustable resistance $R$, a manganin resistance $M$ of 0.232 $\mathrm{ohm}$, and the experimental wire. The difference of potentials between the ends of the experimental wire, and between the ends of the manganin resistance, was measured by the voltmeter V, the resistance of the experimental wire calculated, and the variable resistance $R$ adjusted so as to keep the specific resistance of the experimental wire constant. The thickness of the wires was $0 \cdot 25$ millim., their length about 170 millim., and the loss of weight was determined which they underwent after two bours' glowing. The bydrogen used was prepared from chemically pure zinc and dilute sulphuric acid. To prepare nitrogen the oxygen was removed 
from atmospheric air by phosphorus, and the remaining gas passed through a solution of potassium permanganate, and over caustic potash and phosphoric pentoxide. As an example I may state that a platinum wire at a clear red heat lost 0.84 per cent. of its weight in two hours; at a white heat 3.89 per cent.; the initial weight in both cases being 170 milligrammes, and the surrounding atmosphere air.

The following results were obtained from experiments with atmospheric air at ordinary pressure :-

(a) For both platinum and palladium wires the loss by disintegration decreases as the glowing is continued. Thus in one set of experiments the same platinum wire was used six times consecutively, each experiment lasting two hours, and the temperature of the wire being the same in each. The loss of weight gradually decreased from 0.68 per cent. of the original weight in the first experiment to 0.11 per cent. in the sixth. This phenomenon was observed without exception. for both platinum and palladium wires.

(b) The amount of disintegration is the same whether the air be dry or moist.

(c) The amount of disintegration was not altered by surrounding the glowing wire with a brass tube kept at zero potential by metallic connexion with the water-pipes of the laboratory.

As the pressure of the air decreased the disintegration decreased in the case of platinum, but increased for palladium. Thus in an experiment with air at atmospheric pressure the loss of weight of a platinum wire after two hours was $\mathbf{1 . 6 5}$ per cent. of its original weight, while at the same temperature with air whose pressure was 1.25 millim. the loss after two hours was 0.64 per cent. For a palladium wire the loss was 0.66 per cent. at atmospheric pressure and 11.84 per cent. at pressure 1.25 millim. This result was confirmed by three experiments with platinum and four with palladium.

In hydrogen platinum does not disintegrate even at a clear white heat, while palladium undergoes a very much smaller loss of weight than in air. Thus for a palladium wire the loss of weight after two bours was $0.66^{\circ}$ per cent. in air at atmospheric pressure, 0.096 in hydrogen at atmospheric pressure, and 0.02 per cent. in hydrogen whose pressure was 3 millim, the temperature being the same in each case.

In nitrogen the disintegration is exceedingly small, for both platinum and palladium wires. After two hours the loss of weight of a platinum wire was 0.002 per cent. in nitrogen at atmospheric pressure, while in nitrogen at pressure 3 millim. it was zero. For a palladium wire the losses were 0.04 per cent. at atmospheric pressure, and zero at 3 millim. pressure; 
the loss in air at atmospheric pressure in this ease was $1 \cdot 14$ per cent at the same temperature.

The experiments described above show that the disintegration in air is conditioned by the presence of oxygen, as Nahrwold thought. They do not prove that the presence of both nitrogen and oxygen may not be a necessary condition. Kaufmann, however, has found that in pure oxygen the disintegration is six times as great as in ordinary air.

LIV. Notices respecting New Books.

Outlines of Physical Chemistry. By A. REYCHLER, Professor of Chemistry in the University of Brussels. Translated by Dr. J. MeCrae, Demonstrator of Chemistry, Yorkstive College, Leeds.

London: Whittaker \& Co., 1899.

' THE student who wishes to acquire a knowledge of the elements of physical chemistry will find this volume well adapted to his purpose. It assumes the reader to be acquainted with the simpler phenomena of physics, and to have worked through courses of inorganic and of organic chemistry. The laws of the gaseous state, the determination of vapour-densities, and the cases of abnormal vapour-density are first described; these are followed by a discussion of Dulong and Petit's law, and the corresponding law of Neumann for compound molecules. The subjects of valency and the use of structural formulæ complete this section of the work, which is devoted to fundamental theories. The second portion, treating of the three states of ma!ter and their special propertie;, in detail, introduces the kinetic theory of gases and the phenomena of transition from gas to liquid; the discussion of liquids includes molecular refraction, rotation of plane of polarization and stereochemistry, osmotic pressure, and vapour pressure of solutions. In the third part thermo-chemistry and electro-chemistry are described, the latter leading naturally to the special properties of salt solutions and the ionic theories. The fourth and last section includes chemical dynamics, with examples of equilibrium and of reactions taking place at a measurable rate. It will thus be seen that the book covers much ground, and is therefore necessarily of an elementary character. The relative inportance of the various parts of the subject is well represented by the amount of description given to them, so that the student may obtain a good idea of the nature and extent of the subject.

The part of the work performed by Dr. MeCrae has not been merely that of the translator. By collaboration with the author he has secured the almost simultaneous issue of the revised Belgian edition of the work and of the present translation of it. We learn from the author's preface that many improvements on the original edition have resulted from suggestions by the late Dr. F. Hurter, who was engaged on the translation at the time of his death, and by the present translator who las rewritten and completed it.

J. L. H. 